\title{
PLTSa Lebih Cocok di Pantai
}

Oleh Gede H. Cahyana

HU Pikiran Rakyat, 5 September 2014

Ekonomi bukanlah alasan tepat untuk menetapkan apakah PLTSa layak diterapkan di suatu daerah atau tidak. Yang lebih penting adalah alasan kesehatan lingkungan karena alasan ini akan berdampak juga pada kondisi ekonomi, sosial, dan kapasitas pikir anakanak di sekitar PLTSa. Teknologi tidak cukup hanya ditopang (back up) oleh ilmu (sains) tetapi juga mempertimbangkan dampak buruknya pada lingkungan. Kualitas lingkungan ini pun akan kembali pada kualitas kesehatan jasmani, ruhani, dan taraf kecerdasan (intelligent quotient). Teknologi yang berhasil atau suksespun bisa berdampak buruk pada manusia, baik jasmani maupun ruhaninya, apalagi teknologi yang gagal.

Dalam implementasi teknologi, pelibatan sains dan lingkungan perlu diutamakan agar tidak tersesat, tidak sesal kemudian tak berguna. Memandang sebuah teknologi haruslah dilihat sebagai bagian dari lingkungan. Lingkungan menjadi titik tolak dalam memilah dan memilih teknologi. Teknologi di suatu daerah belum tentu cocok dengan kondisi daerah lain karena lingkungannya memang berbeda. Sederhana analoginya. Baju di daerah kutub tidak selalu tepat dikenakan di daerah tropis. Sebaliknya, baju tipis di tropis tidak cocok dikenakan di kutub. Keduanya akan menimbulkan masalah bagi manusia. Pakaian adalah produk budaya, sama dengan teknologi. Bedanya, teknologi memiliki latar riset dan trial-error berkali-kali, bahkan ratusan tahun dan dapat dicoba oleh orang lain karena berlaku universal.

Begitu pun PLTSa. Sebagai produk teknologi yang dilatari oleh sains dan bahkan dari berbagai sains, ia pun memiliki kecocokan atau ketakcocokan dengan lingkungan tempat manusia. Aspek geografi dan geomorfologi mempengaruhinya. Dalam hal PLTSa, aspek hidrogeologi dan meteorologi justru menjadi aspek terpenting. Dua aspek yang disebut terakhir langsung berkaitan dengan hajat hidup orang banyak, yaitu air dan udara. Air meliputi air tanah dangkal - dalam dan air permukaan seperti sungai, danau, waduk. Karena lokasinya di dataran tinggi, dikelilingi oleh pegunungan, Bandung menjadi lokasi 
yang buruk dan membahayakan manusia dan relasi ekologis lainnya apabila dibangun PLTSa.

\section{Pantai, Opsi Solusi}

Laut adalah open dumping raksasa. Geomorfologinya telah menjadi takdir bahwa laut harus berada di tempat terendah dan menampung semua limbah kegiatan manusia. Laut menjadi badan air terbesar di dunia dengan luasan 97\% dari muka Bumi. Selayaknya dimanfaatkan. Salah satunya, tepi laut atau pantai cocok dijadikan lokasi PLTSa. Minimal ada tiga komponen yang menguntungkan kalau membangun PLTSa di laut (pantai).

Yang pertama, tentu saja sebagai "pemunah" sampah. Sebetulnya materialnya tidak musnah, melainkan berubah menjadi materi lain dan energi. Inilah yang terjadi menurut tinjauan termodinamika. Semua sampah di kota-kota pesisir, kalau diterapkan PLTSa, akan direduksi menjadi seukuran onggokan abu saja. Abu bawah (bottom ash) dan abu terbang (fly ash) dapat disimpan di sanitary landfill yang betul-betul aman. Lokasinya juga di pantai, terutama di daerah rendah. Pelan-pelan, sekian puluh tahun kemudian, akan muncullah daratan pantai yang berasal dari abu. Tentu saja bisa digunakan sebagai pulau khusus, misalnya produsen oksigen, atau pelindung dari gelombang tsunami dan badai yang menyebabkan abrasi pantai.

Yang kedua, dengan fasilitas PLTSa, sampah diubah menjadi energi listrik. Selain digunakan di instalasinya, juga bisa dijual ke masyarakat pantai, terutama nelayan dengan harga relatif murah. Semua sampah di desa-desa, di kota-kota di sepanjang pantai bisa diumpankan ke PLTSa. Biaya ditanggung bersama, baik pemerintah desa, kecamatan, maupun kota - kabupaten yang memanfaatkan PLTSa sebagai sumber energy listriknya.

Yang ketiga, bisa juga dibuatkan fasilitas penyulingan air laut, misalnya Multistage Flash Evaporator (MSF) dan reverse osmosis (RO). MSF dapat menghasilkan distilat dengan konsentrasi TDS yang sangat rendah, $50 \mathrm{mg} / \mathrm{l}$. Dapat dilanjutkan dengan RO untuk menghasilkan air berkualitas tinggi, tak hanya untuk minum tetapi juga untuk keperluan 
industri farmasi dan elektronika. Dengan fasilitas seperti ini, masyarakat pantai, kawasan wisata pantai, hotel dan resort juga water front city dapat memperoleh air bersih sekaligus listrik dan daerahnya bebas sampah. Inilah konsep yang cocok dikembangkan. Alih-alih di kota gunung seperti Bandung, PLTSa lebih cocok di pantai karena sekali mendayung dua-tiga pulau terlampaui. Sambil mereduksi volume, massa atau berat sampah, diperoleh energi listrik, air bersih dan bahkan air berkualitas yang bisa langsung diminum. Polusi udaranya bisa direduksi, meskipun tidak $100 \%$, tetapi jelas lebih baik dibandingkan berada di dataran tinggi seperti Bandung. Uap air yang menangkap abu dan gas kemudian menjatuhkannya di laut atau di pantai, dapat mereduksi hembusan kontaminan ke daratan. Kondisi meteorologi pantai ini mendukung reduksi polutan udara. Abunya terperangkap uap air laut dan jatuh ke laut. Udara menjadi relatif bersih. Selain itu, perilaku dispersi dan disolusi atmosfer menurunkan konsentrasi polutan udara.

Pantai juga kaya air, baik air laut maupun air tawar di muaranya atau minimal air payau dengan kadar garam yang lebih rendah daripada air laut. Sumber air bagi PLTSa adalah syarat utama. Di manapun di Bumi ini, pantai adalah sumber air. Air inilah yang digunakan untuk membilas abu bawah dan abu terbang limbah PLTSa. Inilah yang dimaksud dengan pengembangan teknologi yang berwawasan lingkungan. Sains, teknologi dan lingkungan adalah satu kesatuan yang tak terpisahkan.

Simpulan, apabila PLTSa dibangun di pantai, bukan di Bandung, maka diperoleh instalasi pembakar sampah, instalasi pembangkit listrik, dan instalasi penghasil air siap diminum sebagai pasokan untuk kawasan industri di sekitarnya. * 


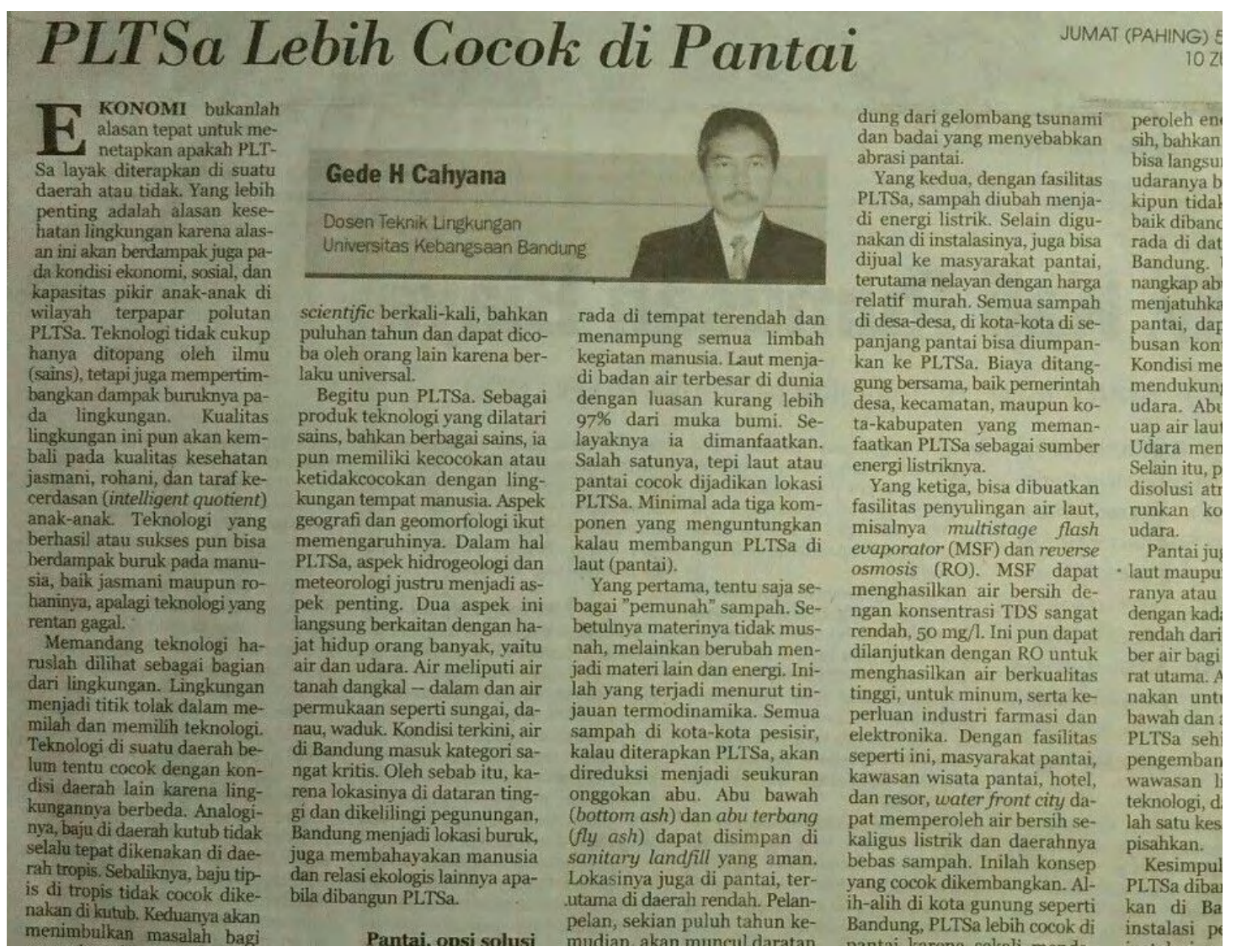

